COLORECTAL CANCER

\title{
Glucagon-like peptide 2 (GLP-2) accelerates the growth of colonic neoplasms in mice
}

\author{
J Thulesen, B Hartmann, K J Hare, H Kissow, C Ørskov, J J Holst, S S Poulsen
}

Gut 2004;53:1145-1150. doi: 10.1136/gut.2003.035212

See end of article for authors' affiliations

Correspondence to: DrJ Thulesen, Naestved Hospital, Department 18, Ringstedgade 61, 4700 Naestved, Denmark; J.Thulesen@dadlnet.dk

Accepted for publication 20 January 2004
Background: Glucagon-like peptide 2 (GLP-2) is an intestinotrophic mediator with therapeutic potential in conditions with compromised intestinal capacity. However, growth stimulation of the intestinal system may accelerate the growth of existing neoplasms in the intestine.

Aims: In the present study, the effects of GLP-2 treatment on the growth of chemically induced colonic neoplasms were investigated.

Methods: In 210 female C57bl mice, colonic tumours were initially induced with the methylating carcinogen 1,2-dimethylhydrazine (DMH) and mice were then treated with GLP-2. Two months after discontinuation of the carcinogen treatment, 135 of the mice were allocated to one of six groups which were treated twice daily with $25 \mu \mathrm{g} \mathrm{GLP}-2,25 \mu \mathrm{g}$ Gly2-GLP-2 (stable analogue), or phosphate buffered saline for a short ( 10 days) or long (one month) period. The remaining 75 mice had a treatment free period of three months and were then allocated to groups subjected to long term treatment, as above. Results: Colonic polyps developed in $100 \%$ of the mice, regardless of treatment. Survival data revealed no statistical significant differences among the different groups but histopathological analysis demonstrated a clear and significant increase in tumour load of mice treated with Gly2-GLP-2. The tumour promoting effect of native GLP-2 was less pronounced but the number of small sized polyps increased following long term treatment.

Conclusions: The present results clearly indicate that GLP-2 promotes the growth of mucosal neoplasms. Our findings highlight the need for future investigations on the effects of GLP-2 in conditions needing long time treatment or with increased gastrointestinal cancer susceptibility.
A growing body of evidence suggests a role for the 33 amino acid peptide glucagon-like peptide 2 (GLP-2) as a mediator of mucosal proliferation in the gut. ${ }^{1-4}$ GLP-2 is co-secreted with GLP-1 from the intestinal enteroendocrine L cells, with the presence of luminal nutrients being the primary stimulus for secretion. ${ }^{4-8}$ The GLP-2 receptor has been localised to the intestine and the hypothalamus, tissues in which GLP-2 has been demonstrated to exert its effects. ${ }^{90-12}$ In addition to mediating mucosal growth, GLP-2 also enhances the activity of several absorptive enzymes together with mediation of an ileal brake effect, indicating that its physiological significance may be to ensure optimal intestinal absorption. ${ }^{2}{ }^{13-16}$

Because of these organ specific actions, supported by several studies in experimental animal models of intestinal diseases, a therapeutic role for GLP-2 has been suggested. $^{781718}$ Recently, clinical improvement was observed in GLP-2 treated patients with functional short bowel syndrome. ${ }^{8}$ This finding, together with experimental data on GLP-2, will undoubtedly lead to more clinical studies. However, little attention has been paid to the potential side effects of GLP-2. In particular, a study on the effects of GLP-2 with respect to intestinal carcinogenesis would be relevant. Thus it has been suggested that patients with inflammatory bowel disease may benefit from treatment with GLP-2. ${ }^{18}$ However, such patients have been considered to have an increased risk of intestinal cancer which might be increased further by GLP-2. Therefore, we investigated the potential tumour growth promoting activity of GLP-2 in the well established 1,2-dimethylhydralazine (DMH) model of colonic cancer in mice which exhibits clinical and pathological features similar to those observed in humans. ${ }^{19}{ }^{20}$ Following tumour induction by repeated exposure to the methylating carcinogen DMH, mice were treated with native GLP-2 or
Gly2-GLP-2, a metabolically stable analogue, for a short or long period. The incidence of colorectal tumours was then examined.

\section{MATERIALS AND METHODS \\ Animals}

Animal studies were approved by the Danish National Committee for Animal Studies. A total of 210 female C57bl mice weighing approximately 18-20 g (eight weeks old) were obtained from the Panum Institute (University of Copenhagen, Copenhagen, Denmark). They were maintained throughout the course of the experiment on water and chow (No 1314; Altromin, Lage, Germany) ad libitum in animal facilities in temperature $\left(21^{\circ} \mathrm{C}\right)$ and humidity $(55 \%)$ controlled rooms with a light-dark cycle of 12 hours.

\section{Experimental procedure}

Two weeks after acclimatisation, mice were allocated to a schedule of subcutaneous injections of DMH (Sigma Chemical Co., St Louis, Missouri, USA). Mice were given a weekly dose of $20 \mathrm{mg}$ DMH per kg body weight every seven days for 12 weeks. The DMH solution was freshly made up in $0.001 \mathrm{M}$ EDTA each week and buffered to a $\mathrm{pH}$ of 6.5 with sodium bicarbonate. In a previous study using the DMH carcinogenic model, different durations of treatment free intervals were used. ${ }^{21}$ Based on these experiences, we chose to divide mice into two groups, with a treatment free interval of two $(2 \mathrm{MO})$ or three months $(3 \mathrm{MO})$. Mice included in the group with a treatment free period of $2 \mathrm{MO}$ were randomised to one of six subgroups and mice in the $3 \mathrm{MO}$ group were randomised into three subgroups. These subgroups were

Abbreviations: GLP-2, glucagon-like peptide 2; DMH, 1,2dimethylhydrazine; PBS, phosphate buffered saline 
Two month treatment free period (2MO)

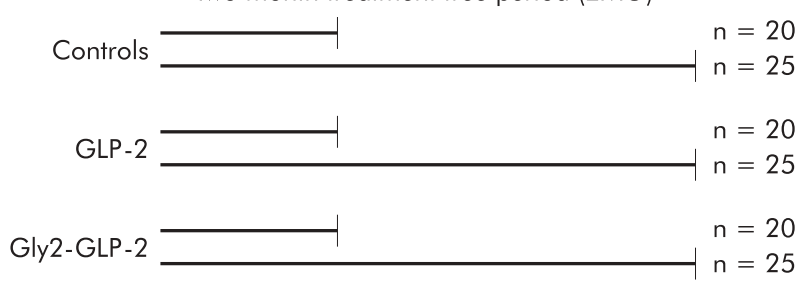

Three month treatment free period (3MO)

Controls $n=25$

GLP-2 $n=25$
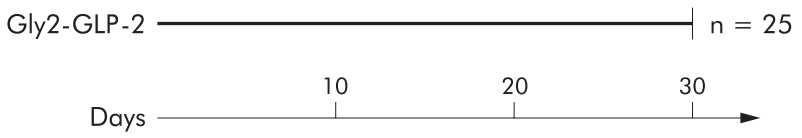

Figure 1 Schematic schedule of the study design with animals allocated into major groups according to the duration of the treatment free interval after the last injection of 1,2-dimethylhydrazine. Mice were then

allocated to subgroups with different durations of treatment, with daily injections of $25 \mu \mathrm{g}$ native glucagon-like peptide 2 (GLP-2), $25 \mu \mathrm{g}$ Gly2GLP-2, or phosphate buffered saline (controls).

treated as depicted in fig 1 . Treatment periods of 10 days and one month, respectively, were chosen to investigate both acute and chronic effects. All treatments consisted of subcutaneous injections twice daily of either $25 \mu \mathrm{g}$ GLP-2 (1-33) (generously provided by Lars Thim, Novo Nordisk, Bagsvaerd, Denmark), $25 \mu \mathrm{g}$ Gly2-GLP-2 (Pepceuticals Ltd, Leicester, UK), or phosphate buffered saline (PBS, control group), all in a volume of $100 \mu \mathrm{l}$ per injection. These dosages were based on previous studies on the intestinotrophic properties of the peptides. ${ }^{22}$ Gly2-GLP-2 is a metabolic stable analogue of GLP-2 with an alanine $\rightarrow$ glycine substitution in position 2 .

During the course of the experiment, animals were observed weekly for evidence of colonic tumours (that is, bloody faeces, rectal prolapse, or cachexia) (table 1).

At autopsy, mice were sacrificed using $\mathrm{CO}_{2}$, and the colon and rectum were filled with $4 \%$ paraformaldehyde and removed. The colon was then cut longitudinally at its antimesenteric site and mounted on a polyethylene plate and fixed for a further 24 hours. Specimens were then flushed with water and stained as whole mounts with alcian green $3 \mathrm{BX} .{ }^{23}$ After staining, they were rinsed with tap water and stored in $70 \%$ ethanol. The colonic surface, immersed in ethanol, was investigated and photographed with a Wild photo microscope. Determination of the number and size of neoplasms was performed in a blinded manner where the origin of the tissue sample was unknown to the investigator. Tumours were categorised according to their size: small $<0.5 \mathrm{~mm}$; medium $0.5-1.0 \mathrm{~mm}$; and large $>1.0 \mathrm{~mm}$ (greatest diameter). Following macroscopic scoring, tissue slices were cut from some of the neoplasms (most cancer suspicious) for histological evaluation. Tissue samples were dehydrated and embedded in paraffin and cut into $10 \mu \mathrm{m}$ sections using a microtome. Sections were stained with PAS haematoxylin aurentia and examined histologically in a blinded manner. Of the 210 mice, 13 died at various time intervals after DMH injection. They were found dead in their cages, and postmortem necrosis hampered inspection of the colonic mucosa.

\section{Statistics}

Results are shown as mean (SEM). Data were analysed by ANOVA with post hoc analysis using Fisher's protected least significant difference test. Probability values of $p<0.05$ were considered significant.

\section{RESULTS}

\section{Survival and body weight}

During the period of DMH injections, no significant differences in mean body weight or weekly weight gain were observed among the groups with an intermediate period of two months $(2 \mathrm{MO})$ or three months $(3 \mathrm{MO})$, respectively, between the last injection of DMH and the first injection of GLP-2 (1-33), Gly2-GLP-2, or PBS (data not shown). Survival rates in Gly2-GLP-2 treated (3MO) mice were lower than those in the other groups at the time of study termination but differences between the groups were not statistically significant (table 2). Only the control group (2MO with one month of treatment) showed a difference between initial and final body weight (table 2). At study termination, mice in the one month Gly2-GLP-2 treated group (3MO) had an increased final body weight compared with controls and the GLP-2 treated groups (table 2).

Table 1 Percentage of mice with the appearance of bloody faeces, rectal prolapse, or cachexia (evidenced by progressive weight loss (>30\% loss compared with initial body weight) and signs of muscle wasting). Colonic neoplasms were induced by 1,2dimethylhydrazine and mice then underwent a treatment free period before daily treatment with native glucagon-like peptide 2 (GLP-2), Gly2-GLP-2, or phosphate buffered saline (controls)

\begin{tabular}{lccc}
\hline & Controls & GLP-2 & Gly2-GLP-2 \\
\hline 2 month treatment free interval (2MO) & & & \\
10 days of treatment & 10 & 11 & 11 \\
$\quad$ Bloody faeces & 40 & 39 & 37 \\
$\quad$ Rectal prolapse & 0 & 6 & 0 \\
$\quad$ Cachexia & 0 & 0 & 0 \\
1 month of treatment & 21 & 15 & 26 \\
$\quad$ Bloody faeces & 0 & 0 & 4 \\
$\quad$ Rectal prolapse & & & \\
$\quad$ Cachexia & 16 & 0 & 11 \\
month treatment free interval (3MO) & 40 & 19 & 28 \\
1 month of treatment & 7 & 7 & 33 \\
$\quad$ Bloody faeces & & & \\
$\quad$ Rectal prolapse & & & \\
$\quad$ Cachexia & &
\end{tabular}


Table 2 Body weight and proportion of tumour bearing animals. Colonic neoplasms were induced by 1,2-dimethylhydrazine and mice then underwent a treatment free period before daily treatment with native glucagon-like peptide 2 (GLP-2), Gly2-GLP-2, or phosphate buffered saline (controls)

\begin{tabular}{|c|c|c|c|}
\hline & Controls & GLP-2 & Gly2-GLP-2 \\
\hline \multicolumn{4}{|l|}{2 month treatment free interval (2MO) } \\
\hline \multicolumn{4}{|l|}{10 days of treatment } \\
\hline Survival (\%) & 100 & 95 & 100 \\
\hline Initial body weight (mg) & $23.6(0.2)$ & $23.1(0.2)$ & $23.3(0.3)$ \\
\hline Final body weight (mg) & $23.2(0.2)$ & $23.3(0.3)$ & $23.5(0.2)$ \\
\hline Tumour bearing animals (\%) & 100 & 100 & 100 \\
\hline Animals with small tumours (\%) & 100 & 100 & 100 \\
\hline Animals with medium sized tumours (\%) & 95 & 77 & 95 \\
\hline Animals with large tumours (\%) & 90 & 72 & 84 \\
\hline \multicolumn{4}{|l|}{1 month of treatment } \\
\hline Survival (\%) & 96 & 100 & 96 \\
\hline Initial body weight (mg) & $23.9(0.2)$ & $23.4(0.2)$ & $23.6(0.2)$ \\
\hline Final body weight (mg) & $22.9(0.2) \dagger$ & $23.2(0.2)$ & $23.8(0.2)^{* *}$ \\
\hline Tumour bearing animals (\%) & 100 & 100 & 100 \\
\hline Animals with small fumours (\%) & 100 & 100 & 100 \\
\hline Animals with medium sized tumours (\%) & 70 & 65 & 78 \\
\hline Animals with large tumours (\%) & 83 & 55 & 83 \\
\hline \multicolumn{4}{|l|}{3 month treatment free interval (3MO) } \\
\hline \multicolumn{4}{|l|}{1 month of treatment } \\
\hline Survival (\%) & 94 & 93 & 75 \\
\hline Initial body weight (mg) & $23.6(0.2)$ & $23.4(0.2)$ & $24.0(0.3)^{*}$ \\
\hline Final body weight (mg) & $23.5(0.2)$ & $23.6(0.2)$ & $24.7(0.4)^{* *}$ \\
\hline Tumour bearing animals (\%) & 100 & 100 & 100 \\
\hline Animals with small tumours (\%) & 100 & 100 & $\ddagger$ \\
\hline Animals with medium sized tumours (\%) & 96 & 96 & 100 \\
\hline Animals with large tumours (\%) & 76 & 63 & 100 \\
\hline
\end{tabular}

\section{Intestinal weight}

Treatment with native GLP-2 for 10 days or one month increased the absolute weight of the small intestine (data not shown) and weight expressed in relation to final body weight (fig 2A). In mice treated with Gly2-GLP-2, both absolute and relative small intestinal weight were higher than in the groups treated with native GLP-2. The relative weight of the colon was not increased following treatment with GLP-2 for 10 days or one month (fig 2B). However, all groups treated with Gly2-GLP-2 had increased weight of the colon, including weight expressed relative to final body weight.

\section{Intestinal neoplasms}

Colonic polyps developed in $100 \%$ of mice (table 2 ).

Tumours were sessile plaques or polypoid lesions, and ranged in size from 0.1 to $5 \mathrm{~mm}$ (greatest diameter). Treatment with Gly2-GLP-2 for one month in both series caused an increased number of all categories of polyps compared with both the control and GLP-2 treated groups (fig 3A, 3B). In the group treated with Gly2-GLP-2 after a treatment free period of $3 \mathrm{MO}$, the number of small tumours was very high and often tumours were more or less confluent which made it impossible to count the exact number of distinct tumours. Treatment with native GLP-2 did not, to a significant degree, affect the number of large or medium sized polyps but the number of small polyps was increased in mice treated with native GLP-2 for one month (2MO) (fig 3C). Mice treated with native GLP-2 (3MO) also had an increased number of small polyps compared with controls.

\section{Histological examination}

All tumours were non-malignant tubular adenomas; medium sized and large polyps were most often pedunculated (fig 4AC). Small polyps were comparable with "aberrant crypt foci". All tumours were confined to the mucosa and there was no penetration of the lamina muscularis mucosa, indicating invasive growth. No differences with respect to tumour histopathology were detected between the groups.

\section{DISCUSSION}

Repeated subcutaneous injections of DMH in mice gave rise to neoplasm formation in the colon of all animals. Neoplasms which predominately occurred in the lower part of colon and in the rectum were diagnosed as tubular adenomas. This may reflect the relative short period of time for tumour development and it seems likely that these adenomas would eventually develop into adenocarcinoma. ${ }^{24}{ }^{25}$ Our data indicate that treatment with Gly2-GLP-2 significantly increased the incidence of colonic neoplasms.

The DMH tumour model has previously been used to test the carcinogenic effects of exogenously administered mitogens (for example, epidermal growth factor) which increased the incidence of anal tumours significantly but had no effect on colorectal polyps. ${ }^{26}$ Interestingly, DMH induced colon tumours in combination with surgical resection or bypass of the intestine has also been investigated..$^{28}$ The latter operations activate adaptive intestinal growth mechanisms and also resulted in an increased incidence of colonic tumours..$^{28}$ It was suggested that tumour promoting factors could be part of the adaptive response and that these factors could include "systemic" rather than local factors. ${ }^{28}$ Because of the present findings, and as endogenous levels of GLP-2 are increased in conditions with adaptive intestinal growth, ${ }^{29}$ it seems likely that these systemic factors with an influence on tumour growth could also include GLP-2.

In the present study, native GLP-2 did not induce growth of colonic neoplasms to the same extent as Gly2-GLP-2. However, it should be noted that the doses of native peptide and analogue used in the present study were not equipotent but chosen solely on previous experience of their intestinotrophic properties on the small intestine and effects on intestinal growth..$^{22}$ The potency of Gly2-GLP-2 is greater than 

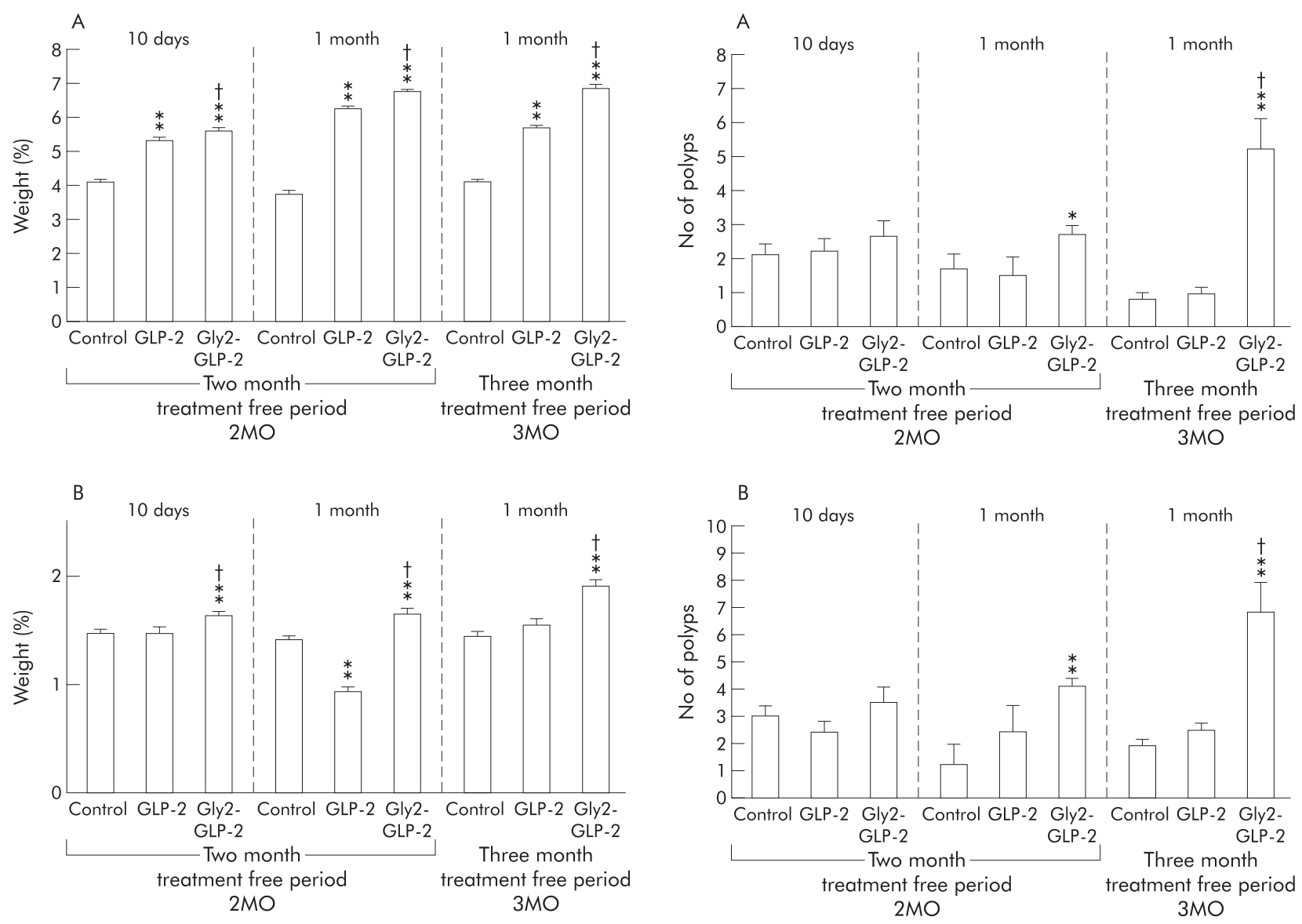

Figure 2 (A) Weight of the small and (B) large intestines as a percentage of final body weight, in mice with colonic neoplasms induced by 1,2-dimethylhydrazine (DMH) and then treated with native glucagonlike peptide 2 (GLP-2), Gly2-GLP-2, or phosphate buffered saline (controls). Mice underwent a treatment free period of two or three months after $\mathrm{DMH}$ and then began daily treatment for 10 days or one month. ${ }^{* *} \mathrm{p}<0.01$ versus controls; $\mathrm{tp}<0.05$ versus native GLP-2.

that of the native peptide, and thus treatment with Gly2GLP-2 induced growth of both the small and large intestine whereas long term treatment with the native peptide induced growth of the small intestine only. Rat GLP-2 receptor RNA levels are present in the colon but the exact cellular localisation of the receptor is still unknown. ${ }^{9} 1012$ However, there appears to be reason to believe that some of the effects of GLP-2 are elicited through other mediators (for example, locally produced trophic factors). These may also be involved in the promotional effects of exogenously administered Gly2GLP-2 or GLP-2 on intestinal neoplasms.

When survival data were evaluated, no statistically significant differences were observed. However, only $75 \%$ of Gly2-GLP-2 treated mice after a three month treatment free period survived until study termination, suggesting that only the healthiest animals in this group survived. Thus there exists a potential risk that the most affected mice in this group were the ones which died during the treatment period. Hence this may have resulted in underestimation of the number of polyps in the Gly2-GLP-2 treated group. Paradoxically, this group had the highest gain in body weight during the study period. However, these mice also had the most pronounced intestinal growth (with colonic polyps) of any of the groups. On average, the small and large intestines weighed approximately $300 \mathrm{mg}$ and $100 \mathrm{mg}$, respectively, more than those of GLP-2 treated animals.

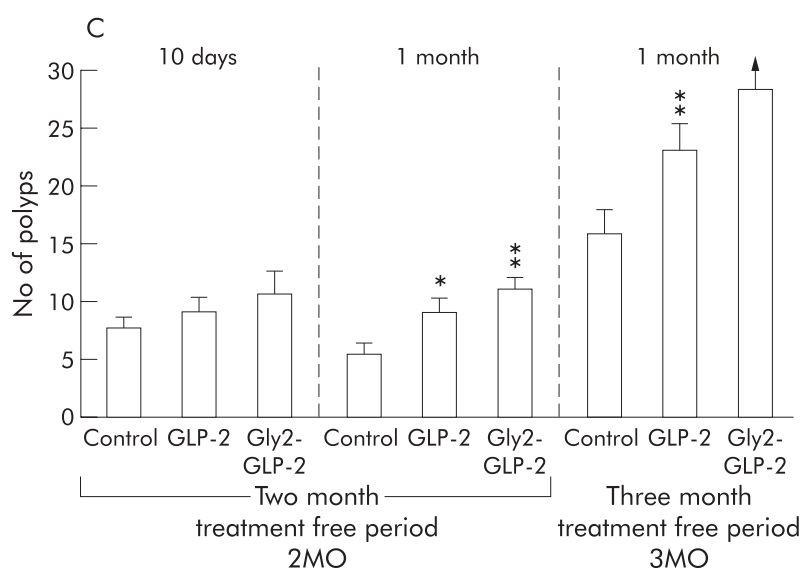

Figure 3 (A) Incidence of large (greatest diameter $>1.0 \mathrm{~mm}$ ), (B) medium (greatest diameter $0.5-1.0 \mathrm{~mm}$ ), and (C) small (greatest diameter $<0.5 \mathrm{~mm}$ ) polyps in the colon. Colonic neoplasms were induced with 1,2-dimethylhydrazine, and mice then underwent a treatment free interval of two or three months before daily treatment for 10 days or one month with native glucagon-like peptide 2 (GLP-2), Gly2-GLP-2, or phosphate buffered saline (controls). ${ }^{*} p<0.05$, ${ }^{* *} p<0.01$ versus controls; $\uparrow p<0.05$ versus native GLP-2. In (C), numerous small sized tumours formed larger conglomerates which made it impossible to count the exact number in the group of $3 \mathrm{MO}$ Gly-2-GLP2 mice.

A major reason for using the DMH model of colonic cancer was the fact that DMH induced colon adenomas and adenocarcinomas are histologically similar to human colon tumours. ${ }^{19}{ }^{30}$ In addition, the general toxicity of DMH and its procarcinogenic derivatives, which cause methylation of DNA, RNA, and other proteins after metabolic activation, is 


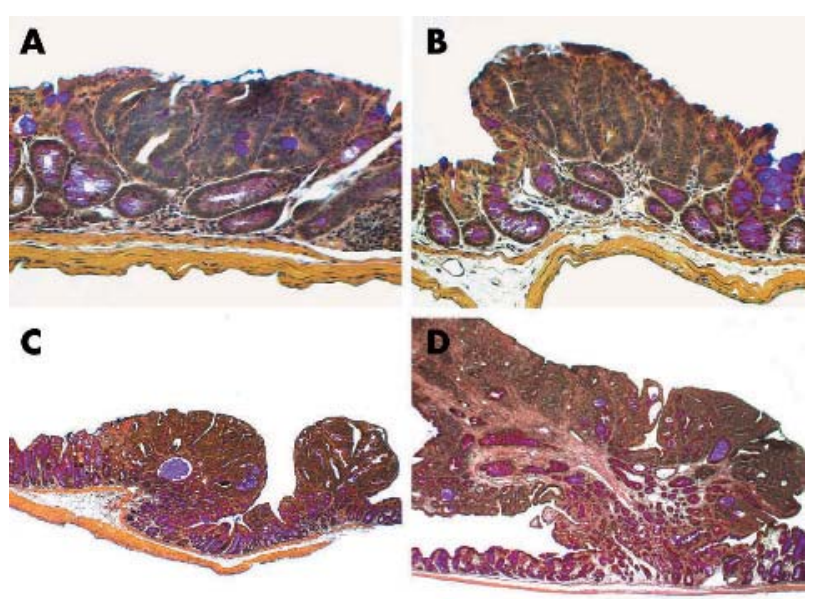

Figure 4 All tumours were non-malignant tubular adenomas confined to the colonic mucosa. (A) Small sized tumours were comparable with "aberrant crypt foci", (B) small sized tumours, (C) medium sized tumours, and (D) large sized tumours were most offen pedunculated. No invasive growth with penetration of the lamina muscularis mucosae was observed. Original magnification $\times 160$.

avoided by the use of small repeatedly administered doses. It has been suggested that the high organ specificity of DMH is due to induction of aberrant patterns of apoptosis in colonocytes, allowing cells which are damaged by methylation to proliferate. ${ }^{31}$ Another major advantage of the DMH model is that the carcinogen is rapidly metabolised and cleared from the body. ${ }^{27}$ Thus enhancement of neoplasia observed in the study by treatment with Gly2-GLP-2 and to a less degree that observed following treatment with native GLP-2 occurred months after sequential exposure to the primary carcinogen, and indicates that GLP-2 promotes the development of existing colonic polyps. A clinical parallel scenario might be when patients who are potential candidates for treatment with GLP-2 have undetected colonic adenomas.

The clinical implications of the present findings are still uncertain. On the one hand, the results are not unexpected as, from a biological point of view, a factor which mediates growth under normophysiological conditions most likely will do the same under pathophysiological conditions, including precancerous conditions. However, the therapeutic use of GLP-2 or its analogues will most likely be in the short term or with intermittent use during a disease state. This may reduce the potential tumour promoting effect. Two obvious caveats of the present study should also be mentioned. Firstly, mice were repeatedly exposed to high doses of a colon specific carcinogen. This contrasts with the chronic low level exposure to DNA methylating agents that human colonocytes may encounter. In addition, mouse colonocytes differ from their human counterparts in that they are generally less sensitive to killing by methylating agents. ${ }^{32}$ Thus it would be premature to extrapolate the results of the present study directly to human diseases. However, the enhanced incidence of enteric and colorectal cancer in patients with inflammatory bowel disease warrants caution if GLP-2 is to be introduced as a therapeutic agent. A growth stimulatory effect of GLP-2 on the intestinal system may accelerate the growth of existing polyps or cancers in the intestine. However, subjects with known existing neoplasms should be excluded from treatment with GLP-2, especially long term or, if treated, closely monitored. On the other hand, endogenous levels of GLP-2 have not been demonstrated to induce carcinogenesis per se but studies investigating the effects of GLP-2 on early stages of tumour development (for example, GLP-2 treatment concomitantly with DMH) should be employed.

In conclusion, the present data clearly demonstrate the stimulatory effects of GLP-2 on the incidence of colonic neoplasms and stress the need for future studies on the tumour promoting properties of GLP-2 (for example, in models with increased cancer susceptibility).

\section{ACKNOWLEDGEMENTS}

This study was supported by grants from the Danish Biotechnology Center for Signal-Peptide Research, the Danish Medical Research Council, and the Novo-Nordisk Foundation. The authors gratefully acknowledge the technical assistance of Grazyna Hahn Poulsen and Jette Schousboe.

\section{Authors' affiliations}

J Thulesen, C Ørskov, S S Poulsen, Department of Medical Anatomy, Section B, The Panum Institute, University of Copenhagen, Copenhagen, Denmark

B Hartmann, K J Hare, H Kissow, J J Holst, Department of Medical Physiology, The Panum Institute, University of Copenhagen, Copenhagen, Denmark

\section{REFERENCES}

1 Drucker DJ, Erlich P, Asa SL, et al. Induction of intestinal epithelial proliferation by glucagon-like peptide 2. Proc Natl Acad Sci U S A 1996;93:7911-16.

2 Brubaker PL, Izzo A, Hill M, et al. Intestinal function in mice with small bowel growth induced by glucagon-like peptide- 2 . Am J Physiol 1997;272:E1050-8.

3 Tsai CH, Hill M, Asa SL, et al. Intestinal growth-promoting properties of glucagon-like peptide-2 in mice. Am J Physiol 1997;273:E77-84.

4 Xiao Q, Boushey RP, Drucker DJ, et al. Secretion of the intestinotropic hormone glucagon-like peptide 2 is differentially regulated by nutrients in humans. Gastroenterology 1999;117:99-105.

5 Rubin D. Nutrient regulation of intestinal growth and adaptation: role of glucagon-like peptide 2 and the enteroendocrine cell. Gastroenterology 1999:117:261-3.

6 Brubaker PL, Crivici A, Izzo A, et al. Circulating and tissue forms of the intestinal growth factor, glucagon- like peptide-2. Endocrinology 1997; 138:4837-43

7 Scott RB, Kirk D, MacNaughton WK, et al. GLP-2 augments the adaptive response to massive intestinal resection in rat. Am J Physiol 1998;275:G911-21.

8 Jeppesen PB, Hartmann B, Thulesen J, et al. Glucagon-like peptide 2 improves nutrient absorption and nutritional status in short-bowel patients with no colon. Gastroenterology 2001;120:806-15.

9 Munroe DG, Gupta AK, Kooshesh F, et al. Prototypic G protein-coupled receptor for the intestinotrophic factor glucagon-like peptide 2. Proc Natl Acad Sci U S A 1999;96:1569-73.

10 Thulesen J, Hartmann B, Orskov C, et al. Potential targets for glucagon-like peptide 2 (GLP-2) in the rat: distribution and binding of i.v. injected (125)IGLP-2. Peptides 2000;21:1511-17.

11 Tang-Christensen M, Larsen PJ, Thulesen J, et al. The proglucagon-derived peptide, glucagon-like peptide- 2 , is a neurotransmitter involved in the regulation of food intake. Nat Med 2000;6:802-7.

12 Bierknes M, Cheng $\mathrm{H}$. Modulation of specific intestinal epithelial progenitors by enteric neurons. Proc Natl Acad Sci U S A 2001;98:12497-502.

13 Wojdemann $M$, Wettergren A, Hartmann B, et al. Glucagon-like peptide-2 inhibits centrally induced antral motility in pigs. Scand J Gastroenterol 1998;33:828-32.

14 Cheeseman $\mathrm{Cl}$, Tsang R. The effect of GIP and glucagon-like peptides on intestinal basolateral membrane hexose transport. Am J Physiol 1996;271:G477-82.

15 Cheeseman CI. Upregulation of SGLT-1 transport activity in rat jejunum induced by GLP- 2 infusion in vivo. Am J Physiol 1997;273:R1965-71.

16 Woidemann M, Wettergren A, Hartmann B, et al. Inhibition of sham feedingstimulated human gastric acid secretion by glucagon-like peptide-2. J Clin Endocrinol Metab 1999;84:2513-17.

17 Boushey RP, Yusta B, Drucker DJ. Glucagon-like peptide (GLP)-2 reduces chemotherapy-associated mortality and enhances cell survival in cells expressing a transfected GLP-2 receptor. Cancer Res 2001;61:687-93.

18 Drucker DJ, Yusta B, Boushey RP, et al. Human [Gly2]GLP-2 reduces the severity of colonic injury in a murine model of experimental colitis. Am J Physiol 1999;276:G79-91.

19 Madara JL, Harte P, Deasy J, et al. Evidence for an adenoma-carcinoma sequence in dimethylhydrazine-induced neoplasms of rat intestinal epithelium. Am J Pathol 1983;110:230-5.

20 Rogers AE, Nauss KM. Rodent models for carcinoma of the colon. Dig Dis Sci 1985;30:87S-102. 
21 Deschner EE, Long FC, Maskens AP. Relationship between dose, time, and tumour yield in mouse dimethylhydrazine-induced colon tumourigenesis. Cancer Lett 1979;8:23-8.

22 Hartmann B, Thulesen J, Kissow H, et al. Dipeptidyl peptidase IV inhibition enhances the intestinotrophic effect of glucagon-like peptide- 2 in rats and mice. Endocrinology 2000;141:4013-20.

23 Poulsen SS, Olsen PS, Kirkegaard P. Healing of cysteamine-induced duodena ulcers in the rat. Dig Dis Sci 1985;30:161-7.

24 Rubio CA, Jaramillo E, Sethy J. Adenomas and carcinomas may be histologically detected in apparently normal coloic mucosa. A study of carcinogen-treated rats. In Vivo 2001;15:299-301.

25 Onose J, Imai T, Hasumura M, et al. Rapid induction of colorectal tumours in rats initiated with 1,2-dimethylhydrazine followed by dextran sodium sulfate treatment. Cancer Lett 2003; 198:145-52.

26 Kingsnorth AN, Abu-Khalaf M, Ross JS, et al. Potentiation of 1,2dimethylhydrazine-induced anal carcinoma by epidermal growth factor in mice. Surgery 1985;97:696-700.
27 Williamson RC, Bauer FL, Oscarson JE, et al. Promotion of azoxymethaneinduced colonic neoplasia by resection of the proximal small bowel. Cancer Res 1978;38:3212-17.

28 Scudamore $\mathbf{C H}$, Freeman $\mathrm{HJ}$. Effects of small bowel transection, resection, or bypass in 1,2- dimethylhydrazine-induced rat intestinal neoplasia. Gastroenterology 1983;84:725-31.

29 Thulesen J, Hartmann B, Kissow $\mathrm{H}$, et al. Intestinal growth adaptation and glucagon-like peptide 2 in rats with ileal-jejunal transposition or small bowel resection. Dig Dis Sci 2001;46:379-88.

30 Thurnherr N, Deschner EE, Stonehill EH, et al. Induction of adenocarcinomas of the colon in mice by weekly injections of 1,2-dimethylhydrazine. Cancer Res 1973;33:940-5.

31 Colussi C, Fiumicino S, Giuliani A, et al. 1,2-Dimethylhydrazine-induced colon carcinoma and lymphoma in msh2(-/-) mice. J Natl Cancer Inst 2001;93:1534-40.

32 Humbert O, Fiumicino S, Aquilina G, et al. Mismatch repair and differential sensitivity of mouse and human cells to methylating agents. Carcinogenesis 1999;20:205-14.

\section{EDITOR'S QUIZ: GI SNAPSHOT}

\section{An unusual case of abdominal pain}

\section{Clinical presentation}

In March 2003, the patient exhibited severe right lower abdominal pain. This 71 year old man was also suffering with severe diabetes mellitus and chronic renal failure, and had undergone resection of the descending colon for mesenteric panniculitis in 2001. On admission, the patient's white blood cell count was $8900 / \mu \mathrm{l}$ and C reactive protein concentration was $8.9 \mathrm{mg} / \mathrm{dl}$. Serum blood urea nitrogen, creatinine, and $\mathrm{K}^{+}$levels were $77 \mathrm{mg} / \mathrm{dl}, 4.8 \mathrm{mg} / \mathrm{dl}$, and $4.6 \mathrm{mEq} / \mathrm{l}$, respectively. An abdominal CT was performed (fig l).

\section{Question}

How does it explain the abdominal pain?

See page 1158 for answer

This case is submitted by:

N Yazaki, K Shiiba, S Ishii, T Mizoi, K Miura, A Oyama, N Tanaka, Y Murata, I Sasaki, Department of Surgery, Tohoku University Graduate School of Medicine, Sendai, Japan

Correspondence to: Dr K Shiiba, Department of Surgery, Tohoku University Graduate School of Medicine, 1-1 Seiryo-machi, Aoba-ku, Sendai 9808574, Japan; k-shiiba@surgl.med.tohoku.ac.jp

doi: $10.1136 /$ gut.2003.023929

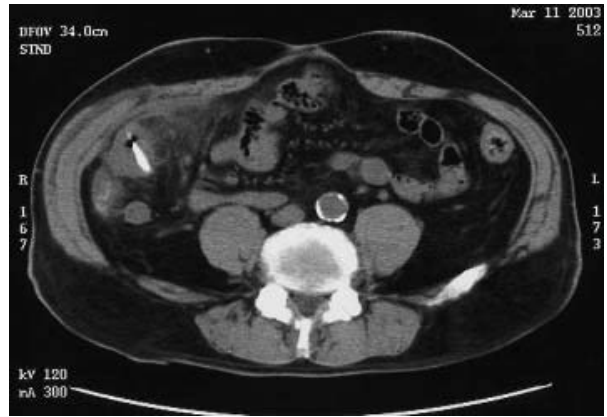

Figure 1 